\title{
Research on the Shock Response Characteristics of a Threaded Connection Using the Thin-Layer Element Method
}

\author{
A'min Yan $^{1}$, Xiaofeng Wang ${ }^{1}$, He Yang ${ }^{2}$, Fenglei Huang ${ }^{1}$ and Aiguo Pi ${ }^{1, *}$ \\ 1 State Key Laboratory of Explosion Science and Technology, Beijing Institute of Technology, \\ Beijing 100081, China; 3120160141@bit.edu.cn (A.Y.); xfwang@bit.edu.cn (X.W.); huangfl@bit.edu.cn (F.H.) \\ 2 Institute of Electronic Engineering, China Academy of Engineering Physics, Mianyang 621999, China; \\ yang.he@caep.cn \\ * Correspondence: aiguo_pi@bit.edu.cn
}

Citation: Yan, A.; Wang, X.; Yang, H.; Huang, F.; Pi, A. Research on the Shock Response Characteristics of a Threaded Connection Using the Thin-Layer Element Method. Appl. Sci. 2021, 11, 5611. https://doi.org/ 10.3390/app11125611

Received: 14 May 2021

Accepted: 15 June 2021

Published: 17 June 2021

Publisher's Note: MDPI stays neutral with regard to jurisdictional claims in published maps and institutional affiliations.

Copyright: (c) 2021 by the authors. Licensee MDPI, Basel, Switzerland. This article is an open access article distributed under the terms and conditions of the Creative Commons Attribution (CC BY) license (https:// creativecommons.org/licenses/by/ $4.0 /)$.

\begin{abstract}
Nonlinear factors such as the contact stiffness and friction damping at the threaded interface of a projectile-fuse system significantly affect the dynamic response characteristics. To obtain the dynamic response of the fuse body accurately during penetration, it is necessary to characterize these nonlinear factors reasonably. Because the existing structural dynamics software cannot effectively deal with nonlinear factors, the thin-layer element method was used to represent the nonlinear factors in this study. By combining the thread elastic model with thin-layer element principles, an effective method for determining the material parameters of the thin-layer element was established theoretically, which provided a different method of determining material parameters, not just relying on experiments. The accuracy of the material parameters was verified based on modal experiments with threaded tubes having different specifications. The errors were within $5 \%$, indicating the reliability of the theoretical determination method for the material parameters. In addition, projectile penetration into a semi-infinite concrete target was tested to verify the accuracy of the thin-layer element modeling. Compared with the 'TIED' constraint method, the resonant frequency obtained with the thin-layer element method was in better agreement with that of the experimental data. The maximum error decreased from 15.7 to $7.8 \%$, indicating that the thin-layer element method could accurately represent the nonlinear factors. Thus, this study serves as a reference for accurately evaluating the dynamic response of the fuse body of a penetrator.
\end{abstract}

Keywords: threaded connection; nonlinear factors; thin-layer element (TLE); projectile-fuse system; frequency response analysis

\section{Introduction}

As threaded connections are easy to install, disassemble, and maintain, the connection between a projectile and fuse is typically a threaded connection. During penetration of a projectile into a hard target, owing to the discontinuity and friction damping of the threaded connection interface [1], there is significant uncertainty in the transmission of overload from the projectile to the fuse, which can cause damage to the key electronic components inside the fuse. Finite element (FE) simulation is an effective method for studying the response of projectile-fuse systems under penetration overload. Because commonly used structural dynamics analysis software cannot deal with nonlinear factors, the threaded contact is usually simplified as a rigid connection for modeling. However, this causes the calculation result to be larger than the actual value. In the field of signal recognition for high-speed penetration of multi-layer hard targets, it is crucial to evaluate the vibration response characteristics of the projectile-fuse system accurately. To improve the accuracy of the simulation, the contact stiffness and friction damping of the threaded connection should be accurately characterized. Therefore, establishing an accurate modeling method for the threaded contact is of great significance for studying the vibration response of the projectile-fuse system. 
Much research has been conducted on the response mechanism of projectile-fuse systems under external loading. Zheng et al. [2] used a split Hopkinson pressure bar (SHPB) to investigate the loosening response of a threaded connection under a series of impact loadings. The correlation between the preload variation and the loosening rotation angle was established using a high-speed camera and digital image correlation (DIC). Zhang et al. [3] proposed a collision model for threaded connections and obtained calculation methods for the collision time and collision force. An FE model was established to study the collision process of the threaded interface between the projectile body and the fuse body. In addition, the wavelet decomposition of the measured deceleration signal indicated the existence of a thread collision frequency between the projectile and the fuse. Guo et al. [4] studied the vibration and energy dissipation efficiencies of flange connections under a series of impact loadings. High-frequency excitation amplified the nonlinear characteristics of the interface, resulting in shock-wave distortion and changes in the shock-wave frequency. As the excitation frequency decreased, the influence of the nonlinear characteristics of the interface also decreased. The above studies investigated the dynamic response of the projectile-fuse system experimentally, and demonstrated that the nonlinear characteristics of the connection interface had a significant impact on the dynamic response of the system. Some works in the literature [5-7] actively introduced nonlinear factors, such as contact stiffness and friction damping, which were in order to adjust the dynamic response characteristics of the combined system. During their works, they adopted a similar method which added coatings on the contact interface and changed the dynamic response characteristics of the combined system by adjusting the material properties of coatings.

In addition, much research has been conducted on the FE simulation of threaded connection interfaces. In particular, to characterize the nonlinear characteristics of the contact interface, the current treatment is to establish a fine solid-thread model in the explicit calculation [8,9]. The establishment of fine solid threads not only increases the complexity of the modeling, it also significantly increases the calculation time. Therefore, threaded connections are often ignored when the structural response is not of concern [10]. However, in the study of the structural response problem, the available structural dynamics software cannot deal with nonlinear factors, and ignoring the threaded connection will have a significant impact on the results. In the literature, the contact interface parameterization method has commonly been used to deal with this type of problem, e.g., through spring elements, general elements [11], the virtual material method [12], zero-thickness elements [13], and thin-layer elements (TLEs) [14]. Because of its easy of modeling and the convenience of its parameter determination, the TLE method has been widely used.

Desai [15] first proposed the concept of TLE modeling in 1984. The interface between the rock and soil was characterized by a TLE with normal contact stiffness and shear stiffness. Zhao et al. [16] used a TLE to represent the contact stiffness of a bolt joint. The variation in the contact stiffness at the bolt interface with the bolt preload was obtained. Lothar et al. [14] applied TLEs to represent the shrunken joints of a two-disk rotor in a generator. The damping and contact stiffness parameters obtained experimentally were coupled to the TLE model. An FE model was then used to predict the response characteristics of the generator. Alamdari et al. [17] introduced TLEs into the FE analysis of threaded pipes coupled to each other by a nut interface. The material parameters of the TLE were adjusted to minimize the residual between the numerical and experimental nonlinear frequency responses. This method significantly reduced the uncertainty of the connection modeling. Schmidt et al. [18] determined the material parameters of a TLE through general experiments. The parameters were coupled to the FE model to study the vibration and damping characteristics of steel composite structures. The numerical modal analysis results were in good agreement with the experimental results. In the above studies, the TLE method was mainly applied to bolt connections or other joint styles, and established at the contact interface to represent the contact stiffness and friction damping. To date, the TLE method has rarely been used to simulate threaded connections. Considering that the 
nonlinear factors of threaded connections also comprise the contact stiffness and frictional damping, the TLE method can be extended to threaded connections for further exploration.

In the application of the TLE method described above, the TLE material parameters were determined by general experiments $[14,18]$ or identified using experimentally measured data $[12,16,17,19]$. Both of these two methods relied on experiments, which complicated the application of the TLE method.

In this study, the TLE method was used to characterize the threaded connection of a projectile-fuse system. The material parameters of the TLE were determined theoretically by combining the elastic model of the threaded connection with the basic principles of the TLE. The projectile penetration into a semi-infinite concrete target was tested. Frequency response analysis of the projectile-fuse system was performed using the TLE method. The accuracy and reliability of the TLE method were verified based on a concrete penetration test.

\section{Experimental Investigation}

\subsection{Experimental Setup}

Several modal experiments of threaded tubes were conducted to investigate the influence of the nonlinear factors of the thread interface on the vibration response characteristics. The specimens were composed of two hollow cylindrical pipes of 45 steel connected by threads. Figure 1a shows the geometries of the threaded tubes. Five sets of threaded tubes (40_3.0, 40_2.0, 40_1.5, 30_2.0, and 50_2.0) were designed, as listed in Table 1. All of the threaded tubes $(6 \mathrm{H} / 6 \mathrm{~g})$ had the same machining precision and assembly accuracy; only the thread length and pitch varied. The label 40_3.0 refers to the thread length $(40 \mathrm{~mm})$ and pitch $(3.0 \mathrm{~mm}$ ). In addition, threadless specimens (L30, L40, and L50) were designed and tested in the same group, as shown in Figure 1b. The label L30 represents a threadless specimen with an overlap length of $30 \mathrm{~mm}$.

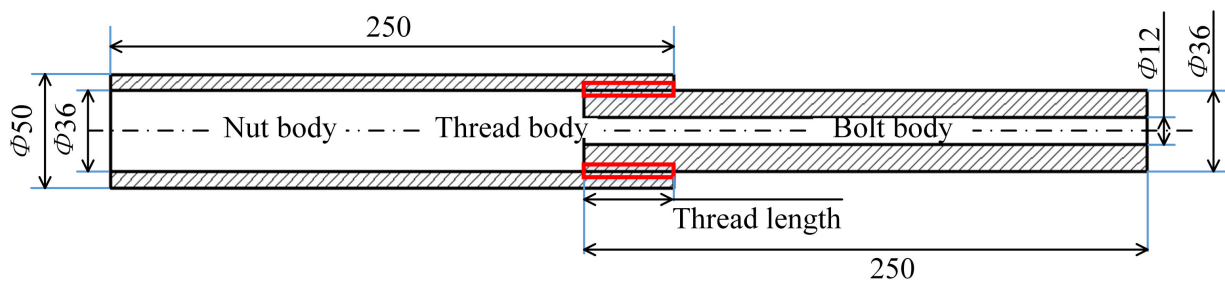

(a)

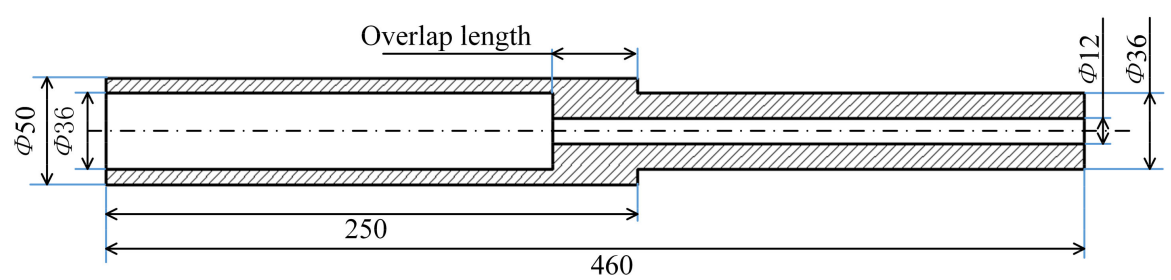

(b)

Figure 1. Test specimens (units: $\mathrm{mm}$ ); (a) threaded specimen; (b) threadless specimen (source elaborated by authors).

Table 1. Threaded specimens for modal tests (source elaborated by authors).

\begin{tabular}{ccc}
\hline No. & Thread Length $(\mathbf{m m})$ & Thread Pitch $(\mathbf{m m})$ \\
\hline $40 \_3.0$ & 40 & 3 \\
$40 \_2.0$ & 40 & 2 \\
$40 \_1.5$ & 40 & 1.5 \\
$30 \_2.0$ & 30 & 2 \\
$50 \_2.0$ & 50 & 2 \\
\hline
\end{tabular}


Figure 2 shows the details of the test setup. The threaded tubes were suspended using elastic ropes to simulate free boundary conditions [18]. An electromagnetic shaker (HEV-20) was used to excite the specimens. The excitation point was selected at location $\mathrm{Z}_{1}$, and two three-directional accelerometers (ENDEVCO 2250AM1-10) were attached at positions $\mathrm{A}_{1}$ and $\mathrm{A}_{2}$ of the threaded tubes. The vibration test system (LMS Inc., Leuven, Belgium) consisted of a data acquisition instrument and vibration analysis software (LMS Test.Lab). The 'MIMO Sweep \& Stepped Sine Testing' module of the LMS Test.Lab software was applied for auxiliary measurement and analysis, and a 16-channel data acquisition instrument was used to receive and process the signal. The sampling rate was set to $20.48 \mathrm{kHz}$. In Figure 2, the swept signal generated by the vibration test system is transferred to the electromagnetic shaker after power amplification. The shaker then receives the swept signal to generate an excitation force. The excitation force is collected by a force transducer (PCB 208C01) installed at the end of the shaker and sent back to the vibration test system. Thus, a feedback loop is formed to maintain a stable excitation force.

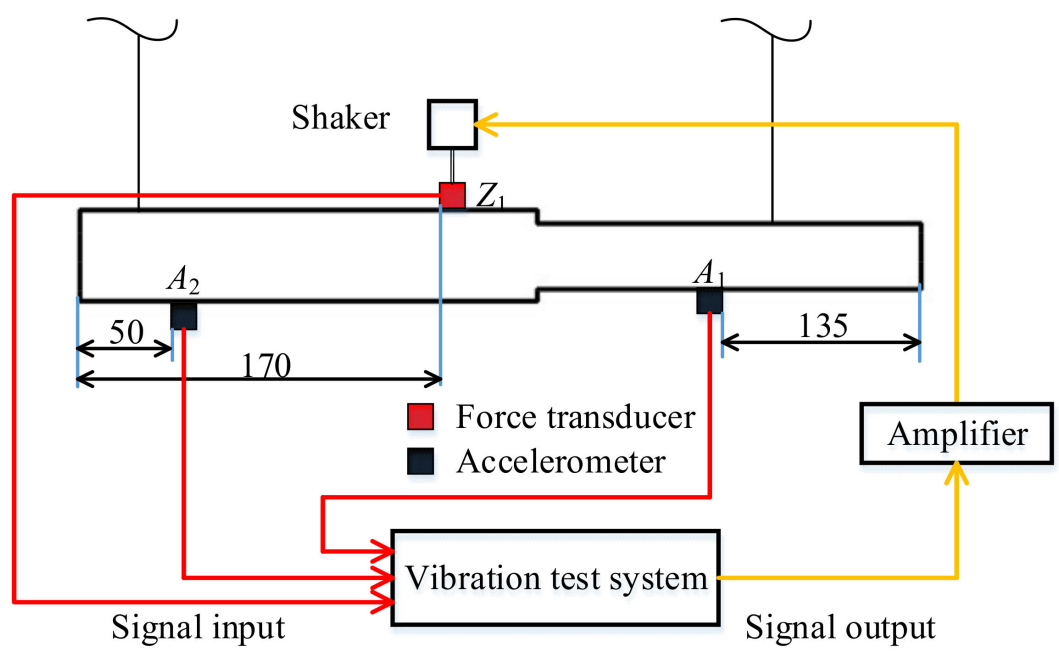

Figure 2. Details of the test setup (source elaborated by authors).

\subsection{Modal Test of the Threadless Structure}

The swept-sine signal can ensure the repeatability of the experiment and is easily used to measure the natural frequency and frequency response function [20]. Therefore, the swept-sine signal was selected as the excitation signal. The swept range of 100 to $5000 \mathrm{~Hz}$ could cover the first three order frequencies of the structure. The swept speed and excitation level were $5 \mathrm{~Hz} / \mathrm{s}$ and $0.1 \mathrm{~N}$, respectively. Figure 3 illustrates the frequency response function (FRF) measured at location $\mathrm{A}_{2}$ of the threadless specimen (L40). The first-, second-, and third-order modal frequencies are 938.26, 2669.86, and $4582.51 \mathrm{~Hz}$, respectively. The obtained FRF has sharp peaks, and the peaks are symmetrical with respect to the resonance, indicating that frictional damping is negligible and the FRF has prominent linear characteristics. For comparison with the experimental results, we obtained the first three order frequencies of the threadless specimen (L40) using the MD/Nastran software, as indicated in the second row of Table 2. The errors between the test and simulation are $1.1,1.3$, and $-0.2 \%$, respectively. The difference can thus be considered negligible, which confirms that the threadless specimen has no nonlinear factors. Because of the negligible difference between the test and FEM in the threadless structure, we used the simulation results instead of experimental results to investigate the threadless structures (L30 and L50), as indicated in Table 2. 


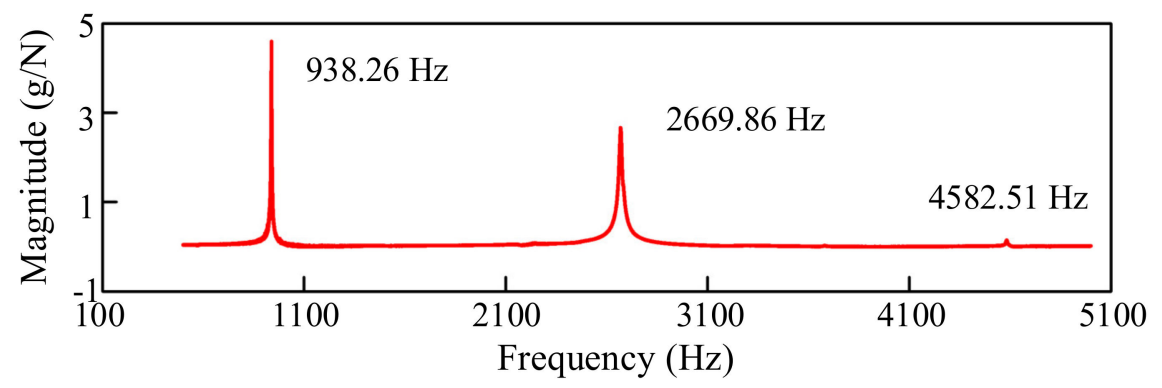

Figure 3. Measured FRF at sensor location $\mathrm{A}_{2}$ of the threadless specimen (source elaborated by authors).

Table 2. First three order frequencies of the threadless specimen from the FEM (source elaborated by authors).

\begin{tabular}{cccc}
\hline No. & 1st $\mathbf{( H z )}$ & 2nd $\mathbf{( H z )}$ & 3rd $\mathbf{( H z )}$ \\
\hline L30 & 903.06 & 2595.30 & 4398.10 \\
L40 & 948.50 & 2704.40 & 4572.90 \\
L50 & 998.47 & 2816.30 & 4772.20 \\
\hline
\end{tabular}

\subsection{Modal Test of the Threaded Structure}

\subsubsection{Nonlinear Behavior of the Threaded Specimen}

There are three states associated with a mechanical joint subjected to increased loading: sticking, micro-slip, and macro-slip. The transition from one state to another alters the interface stiffness and frictional dissipation, which corresponds to the hysteresis mechanism [21]. The thread contact surface appears to stick under a low excitation force. However, with the gradual increase in the excitation, the contact status transforms from sticking to micro-slip or even macro-slip. The effect of nonlinear factors on the vibration behavior will gradually increase. The contact characteristics of threaded connections are generally affected by several factors, such as the roughness, lubrication, and thread preload. In this experiment, the thread preload was determined as a factor in the investigation of the two connection states (tight and loose). Because the thread preload cannot be accurately quantified, the loose thread state was obtained by turning the tight thread back one turn. The excitation levels were 0.8 and $0.1 \mathrm{~N}$. To improve the measurement precision, the segmented swept method was applied to the threaded specimen (40_2.0). The excitation frequencies were divided into three sections: 100-1500, 2000-3500, and 3500-5000 Hz. The swept speed was $5 \mathrm{~Hz} / \mathrm{s}$. Table 3 presents the measurement results.

Table 3. First three order frequencies of the threaded tube (40_2) under four conditions (source elaborated by authors).

\begin{tabular}{ccccc}
\hline Preload & Excitation Force $\mathbf{( N )}$ & 1st $\mathbf{( H z )}$ & 2nd $\mathbf{( H z})$ & 3rd $\mathbf{( H z )}$ \\
\hline \multirow{2}{*}{ Tight } & 0.8 & 814.18 & 2560.85 & 4214.57 \\
& 0.1 & 815.84 & 2561.12 & 4218.47 \\
Loose & 0.8 & 748.84 & 2482.92 & 3983.21 \\
& 0.1 & 753.92 & 2492.59 & 4046.01 \\
\hline
\end{tabular}

In Table 3, each natural frequency of the threaded tube decreases by varying degrees compared with the threadless specimen (L40), and the natural frequency of the loosely connected thread decreases more significantly. In addition, when the excitation level increases from 0.1 to $0.8 \mathrm{~N}$, the natural frequencies of the tightly connected threads change slightly, whereas the natural frequencies of the loosely connected threads change significantly. This indicates that the increase in the excitation level does not change the contact state of the tight thread; however, the contact state of the loose thread changes from sticking to microslip or macro-slip. Figure 4 shows the FRF curves of the threadless specimen (L40) and 
threaded specimen (40_2.0) obtained in the experiments and FEM. It can be seen that the FRF of the threadless specimen obtained with the FEM appears similar to that obtained in the experiment. The first natural frequency is $948.5 \mathrm{~Hz}$, with an error of $1.1 \%$ compared with the experiment. In addition, compared with the threadless structure, the measured natural frequency of the threaded specimen decreases from 938.26 to 815.84 and $753.92 \mathrm{~Hz}$. The first natural frequency of the loosely connected thread decreases more obviously, indicating that the loose connection state is more significantly affected by nonlinear factors than the tight connection state.

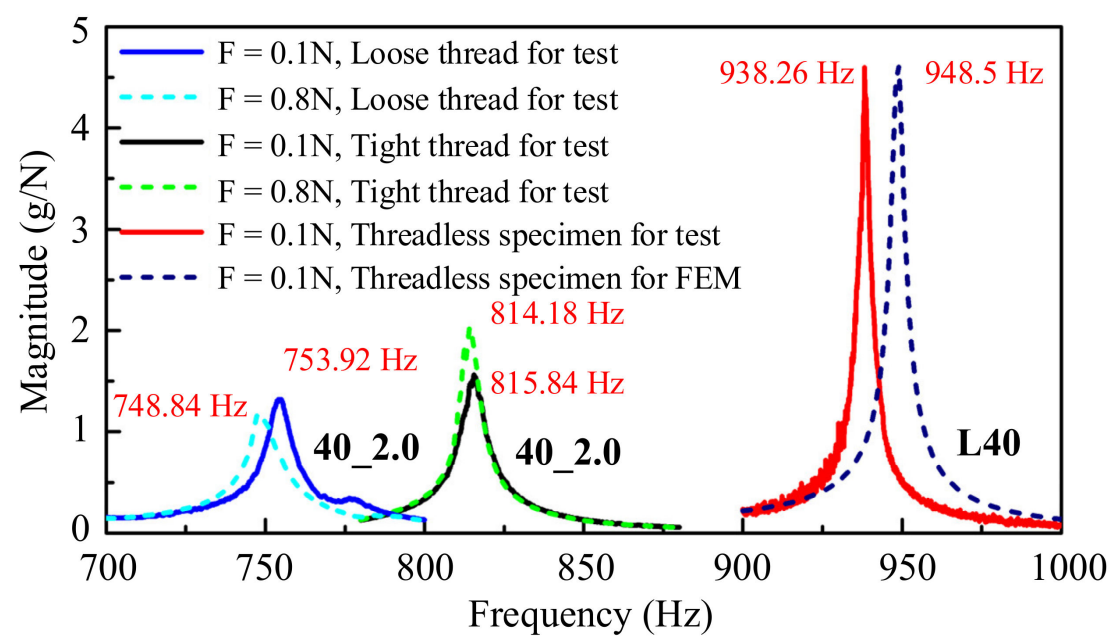

Figure 4. FRF curves of the threadless specimen (L40) and threaded specimen (40_2.0) (source elaborated by authors).

The FRF of the loosely connected thread is compared with that of the tightly connected thread. It can be seen that variation in the excitation level will result in the transition of the thread contact state. With increasing excitation force, the first natural frequency of the loosely connected thread decreases from 753.92 to $748.84 \mathrm{~Hz}$, and the amplitude of the FRF peak decreases from 1.32 to 1.18. This results from the transition from sticking to the micro-slip or macro-slip state of the thread contact with the increase in the excitation level. Accordingly, the frictional damping increases, causing the amplitude and natural frequency to decrease simultaneously. For the tight connection, the first natural frequency decreases slightly from 815.84 to $814.18 \mathrm{~Hz}$, and the amplitude of the FRF peak increases from 1.55 to 2.02 as the excitation force increases. Thus, the tight connection exhibits an entirely different form from that of the loose connection. It is concluded that the tightly connected threaded contact is initially in the sticking state, and the increase in the excitation level does not alter the thread contact state. Therefore, to ensure the simulation precision, it is not advisable to treat the threaded contact as a 'TIED' constraint. The thread contact state should instead be accurately characterized according to the actual situation of the thread contact.

\subsubsection{Modal Tests of Threaded Structures with Different Specifications}

Because the loosely connected thread is a non-working condition, the tight connection state was adopted for subsequent calculations of the thread connection axial stiffness. To study the influence of the thread pitch and length on the vibration response characteristics, several modal experiments were performed for tightly connected thread structures with different thread pitches and lengths. The excitation level had little effect on the results of the tightly connected thread. Therefore, the excitation level was selected as $0.1 \mathrm{~N}$. Moreover, other experimental conditions were the same as those described in Section 2.3.1. Table 4 lists the first three order frequencies of the threaded specimens in the modal tests. It can be seen that the change in pitch has a negligible effect on the frequency of each order. Each natural frequency varies slightly as the pitch decreases. However, each natural frequency 
increases significantly as the thread length increases. This results from the increase in the structural stiffness of the threaded connection with the increase in the thread length.

Table 4. First three order frequencies of the threaded specimens in the modal tests (source elaborated by authors).

\begin{tabular}{cccc}
\hline No. & 1st $\mathbf{( H z )}$ & 2nd $\mathbf{( H z )}$ & 3rd $\mathbf{( H z )}$ \\
\hline 40_3.0 & 804.58 & 2529.71 & 4197.04 \\
$40 \_2.0$ & 815.84 & 2561.12 & 4218.47 \\
$40 \_1.5$ & 824.86 & 2597.08 & 4214.05 \\
30_2.0 & 787.23 & 2488.88 & 4152.55 \\
50_2.0 & 861.48 & 2706.76 & 4438.86 \\
\hline
\end{tabular}

\section{TLE Parameter Determination}

Based on the results of modal experiments, nonlinear factors such as the contact stiffness and friction damping significantly affect the dynamic response characteristics of the threaded structure. To ensure simulation precision, these nonlinear factors should be accurately characterized during the modeling process. The TLE was adopted to represent the contact stiffness and frictional damping of the threaded connection. Based on the thread elastic model, the material parameters of the TLE were determined theoretically.

\subsection{Axial Stiffness of the Threaded Connection}

Figure 5 illustrates the threaded connection, including the nut body and bolt body. The thread is a critical component in connecting the bolt body and nut body. The interaction between the bolt body and nut body is transferred by the thread body. Among the analytical methods for the thread load distribution, the Sopwith method [22] and Yamatoto method [23] have received extensive recognition. These two methods are similar. They both regard the thread as a cantilever beam, and reflect the thread load distribution by the thread axial load distribution. On this basis, Zhang et al. [24] considered the load distribution of threaded connections and proposed an accurate calculation method for the axial stiffness of a threaded connection. The axial stiffness of the threaded connection can be expressed as follows:

$$
K_{a}=\frac{\sinh \lambda l}{\lambda(\cosh \lambda l-1)}\left(\frac{1}{E_{\mathrm{b}} S_{\mathrm{b}}}+\frac{1}{E_{\mathrm{n}} S_{\mathrm{n}}}\right),
$$

where $E_{\mathrm{b}}$ and $E_{\mathrm{n}}$ are the Young's modulus of the bolt body and nut body, respectively; $S_{\mathrm{b}}$ and $S_{\mathrm{n}}$ are the cross-sectional area of the bolt body and nut body, respectively; and $l$ represents the thread length. $\lambda$ can be expressed as follows:

$$
\lambda=\sqrt{\frac{\frac{1}{S_{\mathrm{b}} E_{\mathrm{b}}}+\frac{1}{S_{\mathrm{n}} E_{\mathrm{n}}}}{\frac{1}{k_{\mathrm{ba}}}+\frac{1}{k_{\mathrm{na}}}}},
$$

where $k_{\mathrm{ba}}$ and $k_{\text {na }}$ represent the axial stiffness of the unit length for the threads on the bolt and nut, respectively. These can be expressed as follows:

$$
\begin{aligned}
& k_{\mathrm{ba}}=\frac{1}{\delta_{\mathrm{ba}} \sin \beta}, \\
& k_{\mathrm{na}}=\frac{1}{\delta_{\text {na }} \sin \beta},
\end{aligned}
$$

where $\delta_{\mathrm{ba}}$ and $\delta_{\text {na }}$ represent the elastic deflection caused by the unit force per unit width along the axial direction, and $\beta$ is the lead angle. Zhang et al. [24] presented a calculation method for $\delta_{\mathrm{ba}}$ and $\delta_{\text {na }}$ without considering the contact friction of the threaded teeth. Lu et al. [25] proposed a calculation method for $\delta_{\mathrm{ba}}$ and $\delta_{\mathrm{na}}$ considering the friction force of the threaded teeth. As the consideration of friction complied with the actual situation, the method considering the friction force [25] was adopted for the present calculation. 


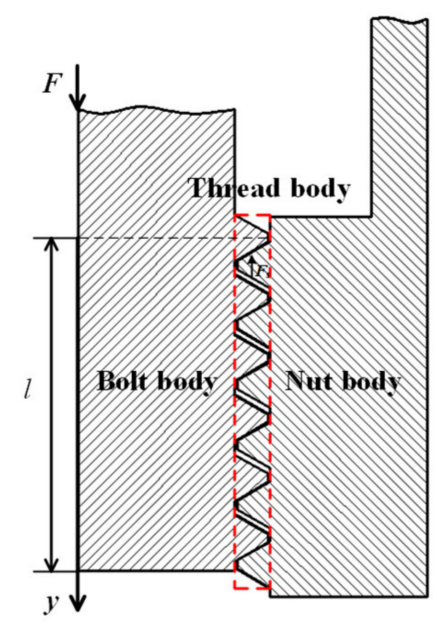

Figure 5. Threaded connection (source elaborated by authors based on [24]).

\subsection{Determination of the TLE Material Parameters}

Figure 6 shows the axial deflection of the TLE under axial force. For the threaded connection under axial force $F$, as shown in Figure 6, the shear stress $\tau$ generated by the axial force is:

$$
\tau=\frac{F}{A}=G_{t} \gamma=G_{t} \frac{u}{t}
$$

where $\gamma$ is the shear angle, $A$ is the contact area, $u$ is the axial displacement, and $t$ is the thickness of the TLE.

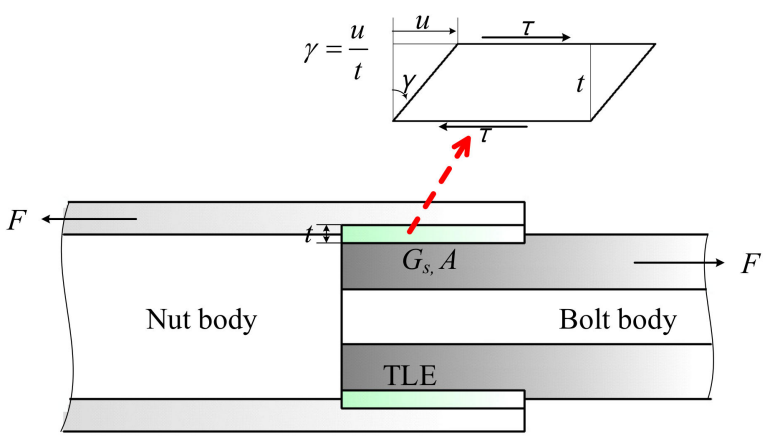

Figure 6. Axial deflection of the TLE (source elaborated by authors based on [13]).

From Equation (4), the axial force $F$ can be expressed as:

$$
F=\frac{G_{t} A}{t} u=K_{\mathrm{a}} u
$$

Substituting Equation (1) into Equation (5), the shear modulus $G_{\mathrm{S}}$ of the TLE can be expressed as:

$$
G_{t}=\frac{K_{\mathrm{a}} t}{A}=\frac{\sinh \lambda l}{\lambda(\cosh \lambda l-1)}\left(\frac{1}{E_{\mathrm{b}} S_{\mathrm{b}}}+\frac{1}{E_{\mathrm{n}} S_{\mathrm{n}}}\right) \frac{t}{A},
$$

where $\lambda$ is calculated using Equation (2).

The normal and tangential contact properties of the interface are independent of each other, and the two tangential contact properties are consistent $\left(c_{55}=c_{66}\right)$. The general form of the constitutive equation for the interface element can be described by [26]:

$$
\left\{\begin{array}{l}
\sigma_{n} \\
\tau_{t x} \\
\tau_{t x}
\end{array}\right\}=\left[\begin{array}{ccc}
c_{11} & 0 & 0 \\
0 & c_{55} & 0 \\
0 & 0 & c_{66}
\end{array}\right]\left\{\begin{array}{c}
\varepsilon_{n} \\
\gamma_{t x} \\
\gamma_{t y}
\end{array}\right\}
$$


where the subscripts $n, x$, and y refer to the contact normal and local $x$ - and $y$-tangential directions, respectively.

The TLE can be simulated as an isotropic material $[19,27]$. In this situation, parameters $c_{11}$ and $c_{55}=c_{66}$ are the Young's modulus $\left(E_{t}\right)$ and shear modulus $\left(G_{t}\right)$, respectively, which define the normal and tangential stiffness of the joint.

\subsection{Reliability Verification of the TLE Modeling}

To investigate the simulation accuracy of the TLE method, we performed a modal analysis of threaded structures with different pitch and thread lengths using the TLE method. From Equation (6), the tangential moduli of the TLE with different pitch and thread lengths were obtained. The Young's modulus could be obtained according to $E=2(1+v) G[16,28]$, where $G$ is the tangential modulus and $v(v=0.269)$ is Poisson's ratio, as indicated in Table 5.

Table 5. Material parameters of the TLE with different types of threaded structures (source elaborated by authors).

\begin{tabular}{cccccc}
\hline No. & $\boldsymbol{L}(\mathbf{m m})$ & $\boldsymbol{P}(\mathbf{m m})$ & $\boldsymbol{K}_{\mathbf{a}}\left(\mathbf{1 0 ^ { \mathbf { 9 } }} \mathbf{N} \cdot \mathbf{m}^{-\mathbf{1}}\right)$ & $\boldsymbol{G}_{\boldsymbol{t}} \mathbf{( G P a )}$ & $\boldsymbol{E}_{\boldsymbol{t}}(\mathbf{G P a})$ \\
\hline $40 \_3.0$ & 40 & 3 & 4.0803 & 1.8039 & 4.5783 \\
$40 \_2.0$ & 40 & 2 & 4.3231 & 1.9112 & 4.8506 \\
$40 \_1.5$ & 40 & 1.5 & 4.4509 & 1.9677 & 4.9940 \\
30_2.0 & 30 & 2 & 3.6630 & 2.1592 & 5.4800 \\
50_2.0 & 50 & 2 & 4.7486 & 1.6795 & 4.2626 \\
\hline
\end{tabular}

Shokrollahi and Adel [29] proposed a new concept for the contact influence area. It is assumed that the joint effects are extended to a region on both sides of the contact interface, which is referred to as the 'joint affected region'. This study extends the thread contact influence area $t / 2$ in the normal direction according to the actual thread tooth height, and a TLE with a thickness of $t$ was used to simulate the thread influence area. The thread of the threaded tubes was an ISO metric triangular thread. For the convenience of modeling, the TLE thickness was determined to be $2 \mathrm{~mm}$ according to the height of the thread teeth, and the TLE length was the thread length. An FE model of the threaded structure was created in MD/NASTRAN, consisting of three parts: an internal thread tube, external thread tube, and TLE, as shown in Figure 7. The internal and external thread tubes and TLE were created using an eight-node solid element (CHEXA), and the contacts between the TLE and threaded tubes were defined as 'tied' constraints. Table 6 lists the material parameters of the threaded tubes [24]. The threaded tubes and TLE were described using a linear elastic material model. The TLE material parameters for different specifications of the threaded structures are listed in Table 5.

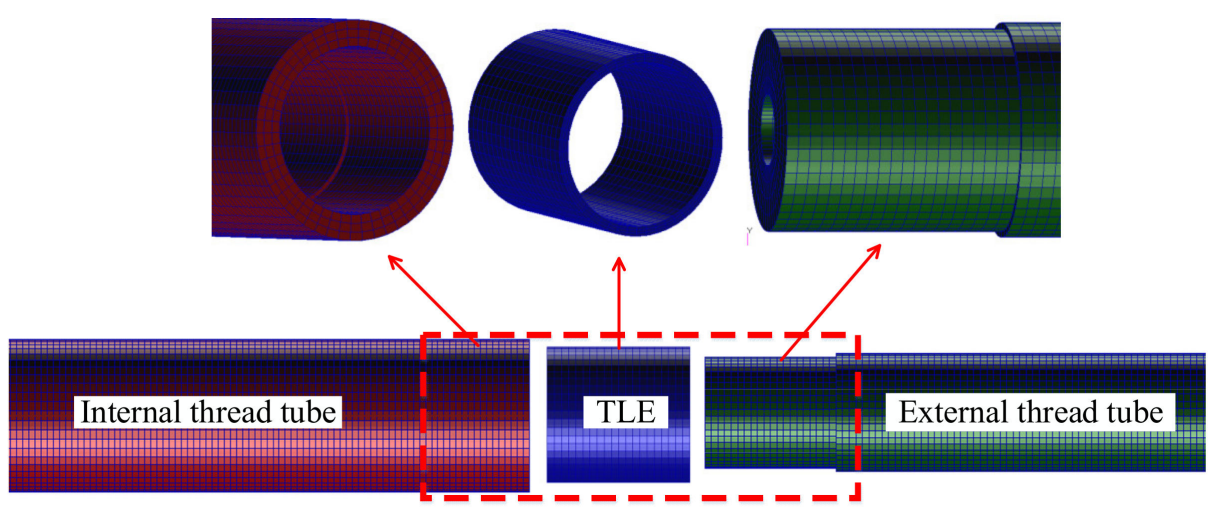

Figure 7. FE models of the threaded tubes and TLE (source elaborated by authors). 
Table 6. Material parameters of the threaded tubes [24].

\begin{tabular}{cccc}
\hline Material & $E(\mathbf{G P a})$ & $v$ & $\left.\rho \mathbf{~} \mathbf{k g} \cdot \mathbf{m}^{-3}\right)$ \\
\hline 45 steel & 211 & 0.269 & 7890 \\
\hline
\end{tabular}

Table 7 lists the first three order frequencies of the threaded structures obtained in the experiments and with the TLE method. Compared with the experiments, the maximum error of the TLE modeling method is $3.6 \%$, and the minimum is $-0.08 \%$. All of the errors are within $5 \%$, which satisfies the precision requirements. In summary, the theoretical determination method for the TLE material parameters is reasonable and reliable for threads with different pitches and thread lengths.

Table 7. First three order frequencies of the threaded tubes in the experiments and TLE method (source elaborated by authors).

\begin{tabular}{cccccccccc}
\hline \multirow{2}{*}{ No. } & \multicolumn{3}{c}{ 1st } & \multicolumn{3}{c}{ 2nd } & \multicolumn{2}{c}{ 3rd } \\
\cline { 2 - 9 } & Test (Hz) & TLE (Hz) & Error (\%) & Test (Hz) & TLE (Hz) & Error (\%) & Test (Hz) & TLE (Hz) & Error (\%) \\
\hline 40_3.0 & 804.58 & 833.58 & 3.6 & 2529.71 & 2612.2 & 3.3 & 4197.04 & 4265.6 & 1.6 \\
40_2.0 & 817.39 & 836.73 & 2.4 & 2567.01 & 2614.9 & 1.9 & 4227.42 & 4273.2 & 1.1 \\
40_1.5 & 824.86 & 838.29 & 1.6 & 2597.08 & 2616.3 & 0.7 & 4214.05 & 4277.0 & 1.5 \\
30_2.0 & 787.23 & 801.11 & 1.8 & 2488.88 & 2511.9 & 0.9 & 4152.55 & 4142.5 & -0.2 \\
50_2.0 & 861.48 & 880.80 & 2.2 & 2706.76 & 2728.5 & 0.8 & 4438.86 & 4435.2 & -0.08 \\
\hline
\end{tabular}

\section{Penetration Test}

To further verify the validity and reliability of the TLE method proposed in this study, a test of projectile penetration into a semi-infinite concrete target was performed using a $152 \mathrm{~mm}$ caliber one-stage light-gas gun. The projectile was machined from 30CrMnSiNi2A high-strength steel, and the necessary heat treatment was performed. Figure 8 shows the projectile geometry. The projectile had an ogive nose with caliber-radius-head (CRH) 3 and a nominal mass of $4.2 \mathrm{~kg}$. A deceleration measurement device was attached to the projectile tail using a threaded connection for acquisition of the deceleration. An accelerometer and electronic components were sealed inside the test device. The structural material of the device housing should be the same as that of the projectile to avoid the influence of different contact surface stiffnesses on the deceleration signal. The specification of the thread body connecting the projectile and measuring device was M42 × 2-6H/6g-33. The thread pitch and length were 2 and $33 \mathrm{~mm}$, respectively. The sampling rate and trigger threshold of the accelerometer were set at $120 \mathrm{kHz}$ and $8000 \mathrm{~g}$, respectively, and a sleep time of $50 \mathrm{~min}$ was set to prevent false triggering of the measurement device. A C40 concrete target plate with a diameter of $120 \mathrm{~cm}$ and a thickness of $60 \mathrm{~cm}$ was used in the experiment. The measured unconfined compressive strength was $50 \mathrm{MPa}$.

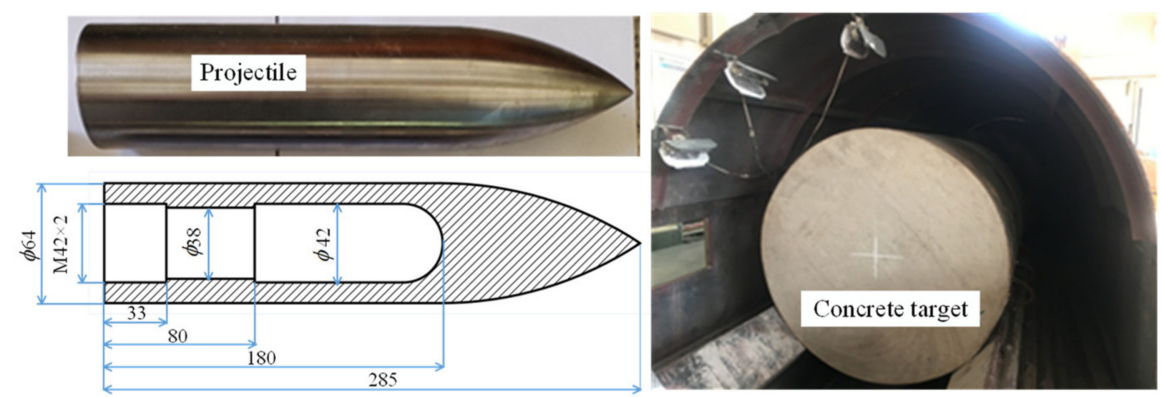

Figure 8. Projectile and target (units: $\mathrm{mm}$ ) (source elaborated by authors). 
The projectile was accelerated along the gun barrel by the instant emission of highpressure gas. After being separated from the sabots, the projectile impacted the concrete target plate vertically at a high speed of $320 \mathrm{~m} / \mathrm{s}$. The projectile target encounter conditions, including the striking velocity and incident attitude angle, were measured using a highspeed camera (Photron/SA5). The deceleration signal was acquired by a deceleration measurement device. The air pressure of the light-gas gun was adjusted to $4.4 \mathrm{MPa}$ according to the projectile mass and striking velocity. After the experiment, the deceleration data in the acceleration data recorder were extracted.

Figure 9 presents the deceleration-time curve in the experiment. In Figure 9, the raw experimental signal was low-pass filtered using cut-off frequencies of 40, 20, and $10 \mathrm{kHz}$. The results indicate that the signal frequency was concentrated within $40 \mathrm{kHz}$. Therefore, we selected the measured signal spectrum within $40 \mathrm{kHz}$ for further research. Figure 10 shows the fast Fourier-transform (FFT) spectrum of the experimental deceleration signal. The first peak of the curve corresponds to the rigid body deceleration with a frequency of $354 \mathrm{~Hz}$, indicating the response frequency of the projectile-fuse system to the penetration loading source. According to the classic theory of vibration, the dominant frequency of the penetration excitation signal is approximately $354 \mathrm{~Hz}$. The rigid body deceleration was obtained by low-pass filtering of the experimental deceleration with a cut-off frequency of $1500 \mathrm{~Hz}$ (Figure 9). The rigid body deceleration represents the real-time resistance signal of the projectile nose. Figure 10 presents the FFT spectrum of rigid body deceleration (red solid line). It can be seen that only one peak exists in the FFT spectrum, with a peak frequency of $354 \mathrm{~Hz}$. This confirms the hypothesis that the frequency of $354 \mathrm{~Hz}$ is the dominant frequency of the penetration excitation signal. Moreover, the frequencies at other peaks are roughly integer multiples of the base frequency $(7919 \mathrm{~Hz})$, indicating the existence of free vibration with a base frequency of $7919 \mathrm{~Hz}$ in the deceleration signal.

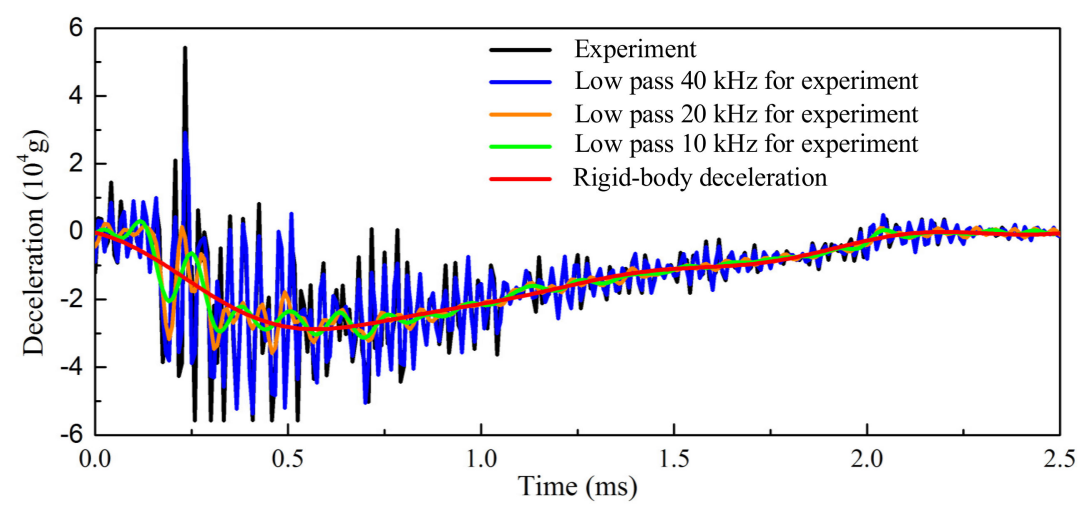

Figure 9. Deceleration-time curve from the penetration experiment (source elaborated by authors).

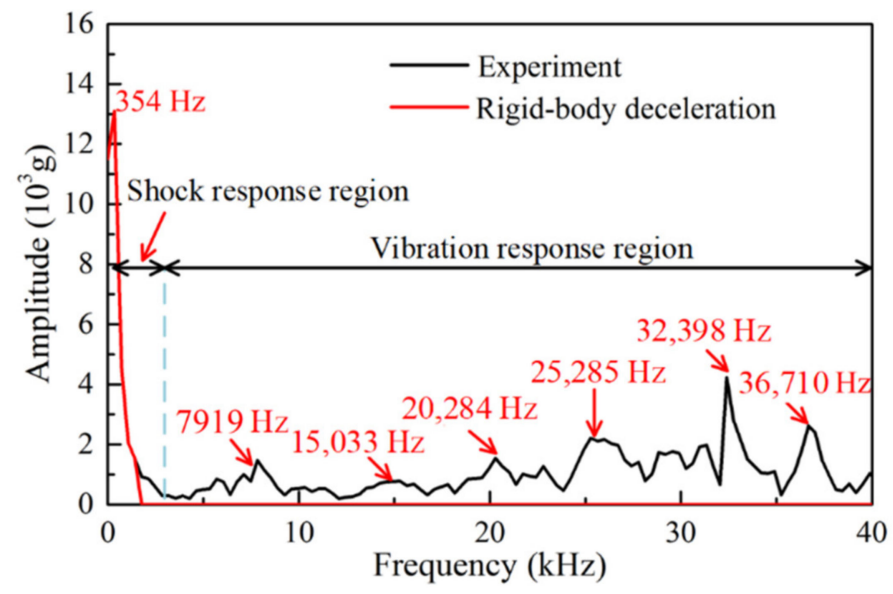

Figure 10. FFT spectrum of the experimental curve (source elaborated by authors). 
Figure 11 shows the high-pass filtering curve of the deceleration signal with a $1500 \mathrm{~Hz}$ cut-off frequency. The change in amplitude of the signal is fitted to an exponential function, indicating that the high-frequency region of the signal is free-damping vibration. The decay rate is generally regarded as an essential indicator for evaluating the amplitude attenuation rate, and it can be expressed as follows:

$$
\delta=\ln \eta=\ln \frac{A_{i}}{A_{i+1}}=\xi \omega_{n} T_{d}=\frac{2 \pi \xi}{\sqrt{1-\xi^{2}}}
$$

where $\eta$ is the decay rate, $\delta$ is the logarithmic decay rate, $A_{i}$ and $A_{i+1}$ are the amplitudes of two adjacent periods, $\xi$ is the damping ratio, $\omega_{n}$ is the natural frequency of the vibration system, and $T_{d}$ is the damping period.

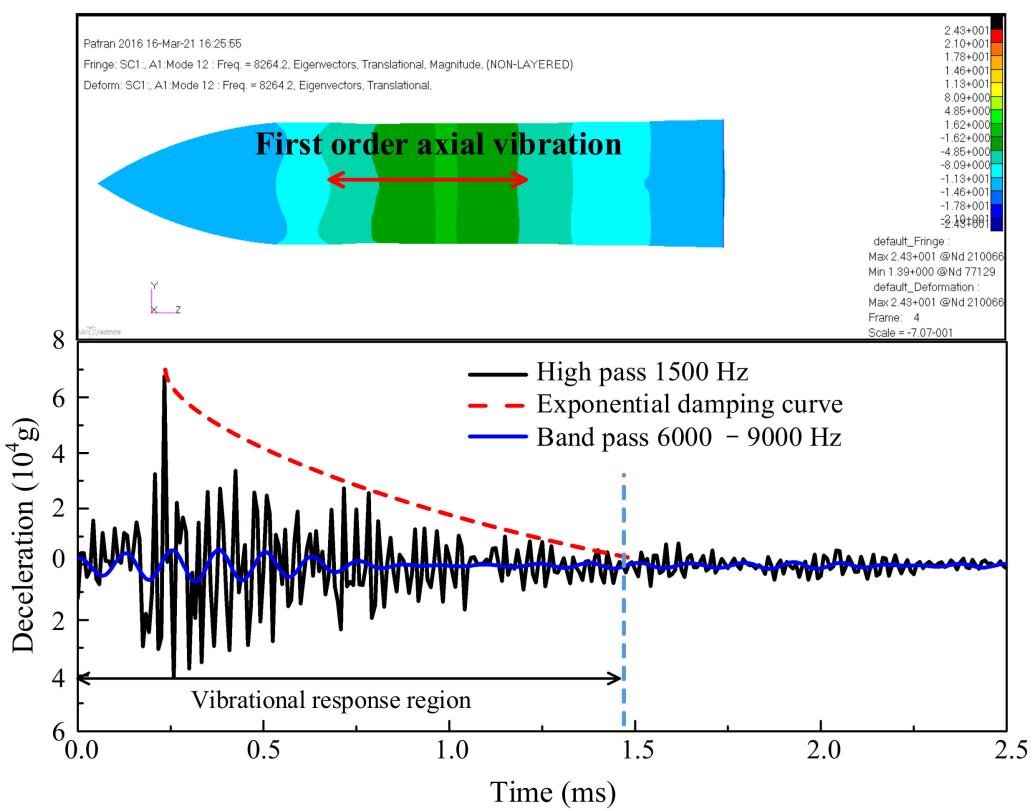

Figure 11. High-pass filtering curve of the deceleration signal with a $1500 \mathrm{~Hz}$ cut-off frequency (source elaborated by authors).

The decay curve in Figure 11 contains five decay cycles, and the damping ratio $\xi$ is approximately 0.06 according to Equation (8). The damping ratio $\xi$ of the penetration vibration response has a significant influence on the signal aliasing. When the damping ratio is relatively small, the decay time of the vibration increases. During penetration of the multi-layer hard target, the vibration signal has not yet been completely attenuated. The residual signal adheres to the penetration signal of the next target layer, which affects the identification of the overload signal. The 'NASTRAN/NORMAL MODES' was used to carry out modal analysis of the projectile-fuse system. The mode shape near a frequency of $7919 \mathrm{~Hz}$ is shown in Figure 11. The vibration form is first-order axial vibration, and the frequency is $8264.2 \mathrm{~Hz}$. Because the FE software cannot deal with the nonlinear factors of the interface contact reasonably, the calculation result will be overestimated. The experimental deceleration signal was band-pass filtered with a cut-off frequency of 6000-9000 Hz, as shown in Figure 11 (blue solid line). The appearance of a complete sine wave indicates the existence of a base frequency. As shown in Figure 11, the first-order axial vibration of the sine wave ceases before the end of penetration, and the end time is approximately $0.8 \mathrm{~ms}$. This indicates that the base frequency is not the dominant frequency of the signal, which can also be seen in the FFT spectrum (Figure 10). The intersection of the damping curve and centerline $(0 \mathrm{~g})$ is defined as the endpoint of the vibration response region. It can be seen that the vibration response terminates at approximately $1.4 \mathrm{~ms}$. In 
Figure 9, the vibration amplitude superimposed on the rigid-body deceleration curve is significantly reduced after $1.4 \mathrm{~ms}$, indicating that the vibration response has ceased.

\section{Frequency Response Analysis Using TLE}

\subsection{Determination of the TLE Material Parameters for the Projectile-Fuse Thread}

The threaded body between the projectile and the fuse comprises an ISO metric triangle thread, and the specification is M42 $\times 2-6 \mathrm{H} / 6 \mathrm{~g}-33$. The materials of the bolt body and nut body are the same as those of the projectile, and the specific parameters are listed in Table 8. Figure 12 shows the influence of the thread friction coefficient on the axial stiffness and TLE shear modulus. As shown in Figure 12, the thread axial stiffness and shear modulus gradually increase as the friction coefficient increases. The thread contact friction coefficient [30] is set to 0.08 . The resulting thread connection stiffness and material parameters of the TLE are listed in Table 9. Only the axial modes are excited during the penetration event. Thus, the axial stiffness associated with the shear modulus should be considered, and the radial stiffness associated with the Young's modulus can be ignored. The Young's modulus of the TLE can be determined directly based on the relationship between the shear modulus and Young's modulus.

Table 8. Material parameters (source elaborated by authors).

\begin{tabular}{cccccccc}
\hline Specification & Processing Precision & Pitch $(\mathbf{m m})$ & Length $(\mathbf{m m})$ & $E(\mathrm{GPa})$ & $\rho\left(\mathrm{kg} / \mathbf{m}^{\mathbf{3}}\right)$ & $v$ & 7800 \\
\hline $\mathrm{M} 42 \times 2-6 \mathrm{H} / 6 \mathrm{~g}-33$ & 6 & 2 & 33 & 220 & 0.284 \\
\hline
\end{tabular}

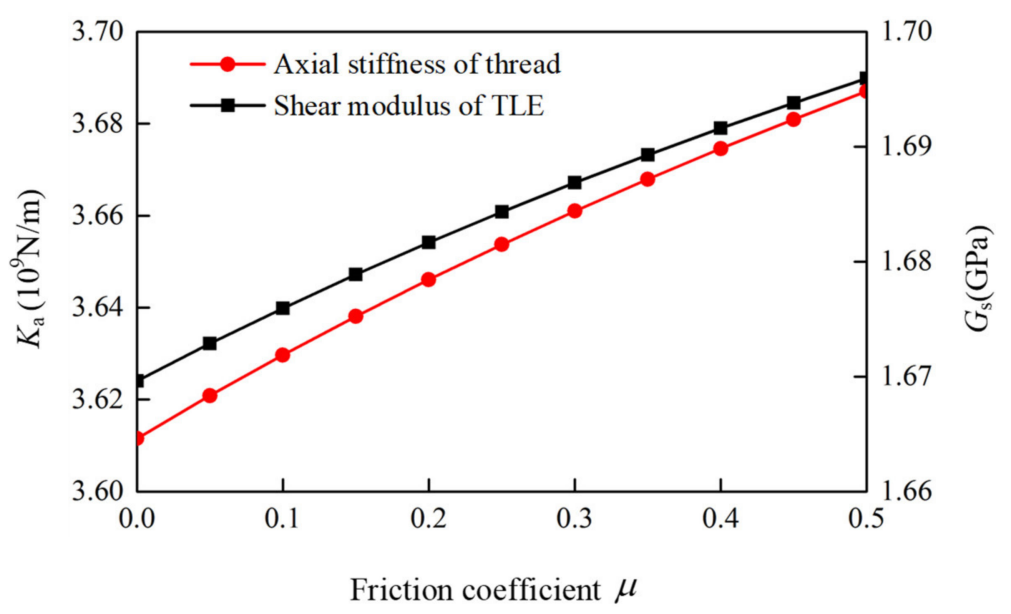

Figure 12. Influence of the thread friction coefficient on the axial stiffness and TLE shear modulus (source elaborated by authors).

Table 9. Threaded axial stiffness and material parameters of the TLE (source elaborated by authors).

\begin{tabular}{cccc}
\hline$K_{\mathrm{a}}\left(\mathbf{1 0 ^ { 9 }} \mathbf{N} \cdot \mathbf{m}^{-\mathbf{1}}\right)$ & $G_{t}(\mathrm{GPa})$ & $v$ & $E_{t}(\mathrm{GPa})$ \\
\hline 3.6368 & 1.67 & 0.284 & 4.29 \\
\hline
\end{tabular}

\subsection{Nodal Force Distribution of the Projectile Nose}

To simulate the real penetration excitation environment, the penetration excitation force should be accurately applied to the projectile nose. The projectile has a symmetrical structure. Therefore, the radial forces cancel each other out for vertical penetration, and only the excitation force in the axial direction should be considered. In the frequency response analysis of the projectile-fuse system, the axial penetration resistance was usually evenly distributed to the nodes [31]. However, this cannot accurately represent the excitation of the projectile nose and affects the dominant frequency distribution. Thus, we propose to 
assign the axial penetration resistance to the nodes of the projectile nose according to the node position.

Figure 13 shows the force analysis on the oval nose of the projectile. Forrestal and Luk [32] proposed the relationship between the radial stress on the cavity surface and the cavity expansion velocity based on the cavity expansion theory. The relationship between the radial stress on the projectile surface and the rigid body velocity is expressed as:

$$
\sigma_{n}\left(V_{z}, \phi\right)=A f_{c}^{\prime}+B \rho\left(V_{z} \cos \phi\right)^{2},
$$

where $\sigma_{n}$ is the radial stress at the projectile surface, $f_{c}^{\prime}$ is the unconfined compressive strength of the concrete target, $V_{z}$ is the rigid body velocity, and $\rho$ is the target density. $A$ and $B$ are target material coefficients, which can be obtained from triaxial tests of the target material. The value of $B$ is generally within a small range around $1.0[32,33]$. For concrete materials, $B$ is approximately 1.0 , and $A(A=S)$ is related to the compressive strength of the concrete material [34]. Based on many experiments, Li and Chen [35] obtained the relationship between $S$ and $f_{c}^{\prime}$ as $S=72.0 f_{c}^{\prime-0.5}$.

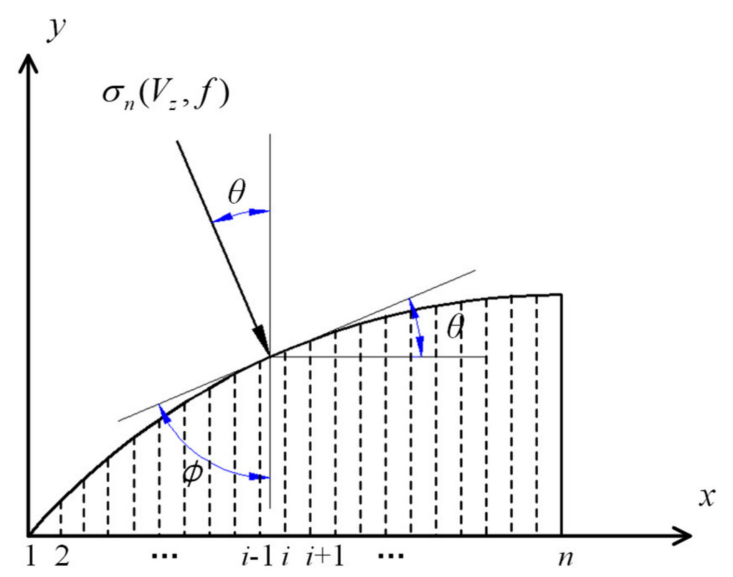

Figure 13. Force analysis on the oval nose of the projectile (source elaborated by authors).

For an area of $d s$ at the projectile nose surface, the axial resistance caused by the radial stress on the projectile surface can be expressed as:

$$
F_{i}=\sigma_{n} d s \sin \theta_{i}=\left(A f_{\mathcal{c}}^{\prime}+B \rho\left(V_{z} \sin \theta_{i}\right)^{2}\right) \sin \theta_{i} d s=\left(\rho V_{z}^{2}\left(\sin \theta_{i}\right)^{3}+S f_{\mathcal{c}}^{\prime} \sin \theta_{i}\right) d s
$$

From Equation (10), it can be seen that the axial resistance at any point is a thirdorder function of $\sin \theta$. To investigate the relationship between $\rho V_{z}^{2}(\sin \theta)^{3}$ and $S f_{c}^{\prime} \sin \theta$ in Equation (10), the curve of $\rho V_{z}^{2}(\sin \theta)^{3} / S f_{c}^{\prime} \sin \theta$ with respect to $V_{z}$ and $\theta_{i}$ is shown in Figure 14 . Considering that the rigid body velocity $V_{z}$ gradually decreases to $0, \rho V_{z}^{2}(\sin \theta)^{3}$ is much smaller than $S f_{c}^{\prime} \sin \theta$ for the low-to-medium speed penetration $(<500 \mathrm{~m} / \mathrm{s})$. Moreover, the closer the location is to the arc-column interface, the smaller $\theta$ is, and the smaller $\rho V_{z}^{2}(\sin \theta)^{3} / S f_{c}^{\prime} \sin \theta$ will be. Therefore, the axial resistance can be regarded as related only to $S f_{c}^{\prime} \sin \theta$.

The projectile was meshed using the mapped method. The numbers of circumferential and axial nodes are $s$ and $n$, respectively (Figure 13).

$$
\left\{\begin{array}{c}
F_{1}+\cdots F_{i}+\cdots+F_{n}=\frac{F}{s}=\frac{m_{p} a}{s} \\
F_{i} / F_{1}=\frac{S f_{c}^{\prime} \sin \theta_{i} d s}{S f_{c}^{\prime} \sin \theta_{1} d s}=\frac{\sin \theta_{i}}{\sin \theta_{1}}=k_{i}
\end{array}\right.
$$

where $F_{1}$ is the axial resistance of the node at the tip of the projectile, $F_{n}$ is the axial resistance of the node at the arc-column interface of the projectile, $F$ is the rigid body resistance in the axial direction, $m_{p}$ is the projectile mass, and $a$ is the rigid body deceleration. 


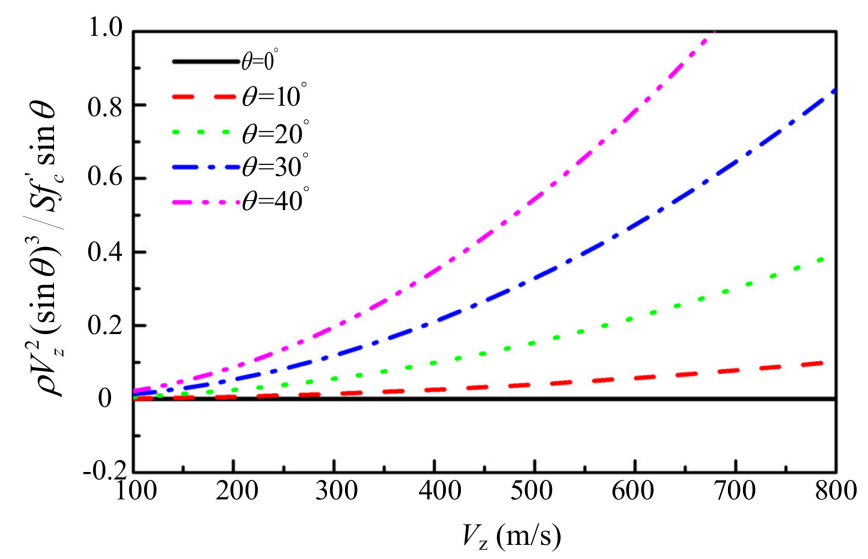

Figure 14. Curve of $\frac{\rho V_{z}^{2}(\sin \theta)^{3}}{S f_{c}^{\prime} \sin \theta}$ with regard to $V_{z}$ and $\theta$ (source elaborated by authors).

From Equation (10), the axial resistance of any node at the projectile nose can be expressed as follows:

$$
F_{i}=\frac{F}{s \sum_{i=1}^{n} k_{i}} k_{i}=\frac{m_{p} a}{s \sum_{i=1}^{n} k_{i}} k_{i}
$$

\subsection{TLE Modeling}

The NASTRAN/FREQUENCY RESPONSE software was used to simulate the penetration response of the projectile-fuse system. The projectile body and fuse body are connected by threads. The vibration response of the fuse cannot be accurately predicted because of the uncertain factors at the threaded contact. The primary uncertainty in threaded connections arises from the contact stiffness and friction damping [30]. Because the commonly used dynamic analysis software cannot correctly deal with nonlinear factors, the TLE was used to characterize the contact stiffness between threaded contacts. In addition, the thread friction damping was described by setting a reasonable damping coefficient for the TLE. According to the height of the thread tooth, the thickness of the TLE was determined to be $2 \mathrm{~mm}$. The length of the TLE was $33 \mathrm{~mm}$, i.e., the threaded length. Figure 15 shows the FE model of the projectile-fuse system. The FE model was composed of three parts: the projectile body, fuse body, and TLE. All of the entities were modeled using eight-node hexahedral elements (CHEXA), and each node had six degrees of freedom. For the convenience of constraint treatment at the contact interface, the element sizes of the projectile body, fuse body, and TLE should be consistent at the thread contact interface. The projectile and fuse were characterized using a linear elastic model. The material parameters are listed in Table 8. The TLE was also characterized by a linear elastic material model, and Table 9 lists the material parameters. The contacts between the two pairs (TLE and projectile, TLE and fuse) were defined as 'tied' constraints.

At the projectile nose, the numbers of circumferential and axial nodes were 120 and 44 , respectively. To satisfy the quality requirements of the hexahedral mesh, the number of circumferential nodes at the tip of the projectile nose was generally reduced during mesh generation. Thus, we allocated the penetration excitation forces by combining the node position with the number of circumferential nodes. In the present simulation, $F$ in Equation (12) refers to the experimental rigid-body deceleration. The magnitudes of each nodal force were obtained using Equation (12). The projectile had a free state without any boundary constraints. 


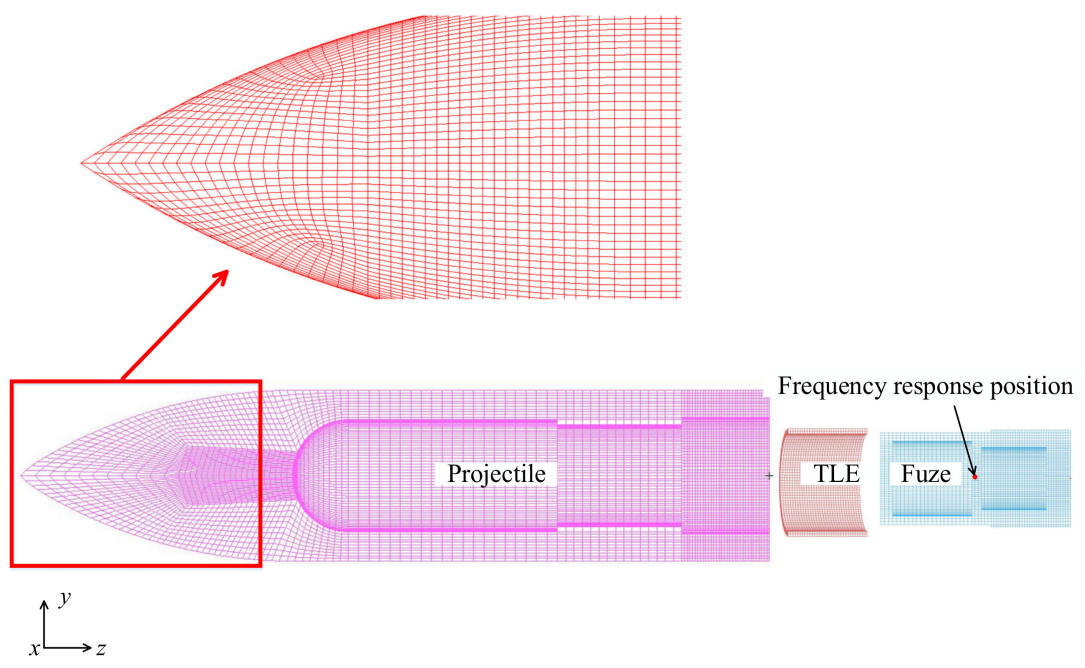

Figure 15. FE model of the projectile-fuse system (source elaborated by authors).

In addition, the damping was incorporated by the complex stiffness matrix $K *$ domain with dissipation multipliers $\alpha_{i}$ and $\beta_{i}$ for the material and joint damping, respectively, and the associated element stiffness matrices.

$$
K *=K+j \sum_{i=1}^{n} \alpha_{i} K_{i}^{(\text {Material })}+j \sum_{i=1}^{n} \beta_{i} K_{i}^{(\text {Joint })},
$$

where $K$ is a real-value stiffness matrix, and $n$ and $m$ are the number of different materials and joints with different properties used in the model, respectively. Material damping is applied to the elements belonging to the components of the projectile-fuse system, and joint damping is realized by applying damping to the TLEs [13]. In the present calculation, the material damping $\alpha$ is $5 \times 10^{-4}$, and the joint damping $\beta$ is 0.03 , determined through a trial-and-error method.

The Lanczos algorithm for the modal superposition method was applied for analysis and solution. The number of desired roots was set to 100 . To meet the $40 \mathrm{kHz}$ output frequency range, the length and number of output frequency steps were $100 \mathrm{~Hz}$ and 400 respectively. One node at the middle partition (accelerometer position) of the fuse was selected as the frequency response point (Figure 15).

Figure 16 shows a comparison of the nodal force distribution methods, including an equal distribution and the distribution according to Equation (12). The frequency response resonance peaks of the nodal force distribution using Equation (12) are concentrated in the frequency band of $30-40 \mathrm{kHz}$, while the resonance peaks of the equal distribution method are concentrated around the first-order frequency. The concentration region of the resonance peaks for the distribution method according to Equation (12) is consistent with the experimental FFT spectrum. In addition, the amplitude variation of the resonance peaks exhibits a similar trend as that obtained in the experiment. Thus, the nodal force distribution method using Equation (12) is more reasonable. Figure 17 shows the FRF curve of the TLE and TIED modeling methods. Compared to the experimental FFT spectrum, it can be seen that the two modeling methods have a similar frequency distribution as the experiment, and only at the frequency of $20,284 \mathrm{~Hz}$ are the resonance peaks obtained by the two simulation methods not noticeable. This is because the vibration at the frequency of $20,284 \mathrm{~Hz}$ is a non-axial vibration mode. Only the nodal force along the axial direction was applied in the FE model. Therefore, this vibration mode was not completely excited. During penetration, it is impossible to guarantee the complete vertical penetration of the projectile. Thus, the resonance peak $(20,284 \mathrm{~Hz})$ appears in the experimental spectrum. Compared with the 'TIED' method, the amplitudes of the FRF curve at each frequency obtained with the TLE method are closer to those of the experimental spectrum. Table 10 lists the resonance frequencies of the TLE method, TIED method, and experiment. Each 
vibration frequency obtained with the TLE method appears closer to the experimental value. The maximum error is $7.8 \%$, indicating that the TLE method can accurately simulate the contact interface of the threaded connection by defining a reasonable damping coefficient of the TLE.

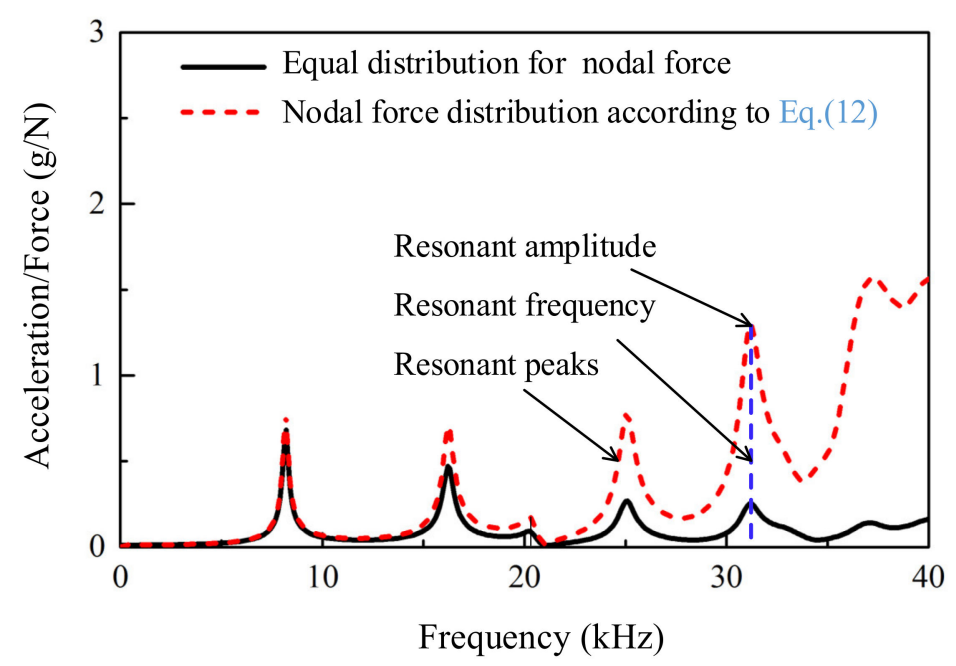

Figure 16. Comparison of nodal force distribution methods (source elaborated by authors).

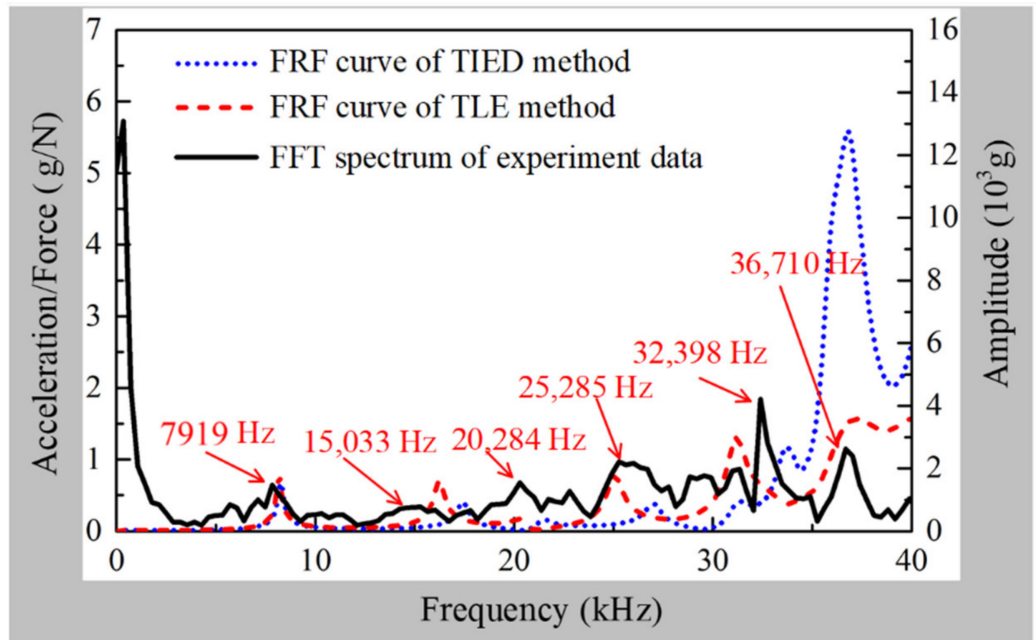

Figure 17. FRF curves of the TLE method and TIED method (source elaborated by authors).

Table 10. Resonance frequencies of the TLE method, TIED method, and experiment (source elaborated by authors).

\begin{tabular}{|c|c|c|c|c|c|c|c|c|c|c|c|c|}
\hline \multirow{3}{*}{$\begin{array}{c}\text { Method } \\
\text { TEST }\end{array}$} & \multirow{2}{*}{\multicolumn{2}{|c|}{$\frac{f_{1}}{(\mathrm{~Hz})(\%)}$}} & \multirow{2}{*}{\multicolumn{2}{|c|}{$\begin{array}{c}f_{2} \\
(\mathrm{~Hz})(\%)\end{array}$}} & \multirow{2}{*}{\multicolumn{2}{|c|}{$\begin{array}{c}f_{3} \\
(\mathrm{~Hz})(\%)\end{array}$}} & \multirow{2}{*}{\multicolumn{2}{|c|}{$\begin{array}{c}f_{4} \\
(\mathrm{~Hz})(\%)\end{array}$}} & \multirow{2}{*}{\multicolumn{2}{|c|}{$\begin{array}{c}f_{5} \\
(\mathrm{~Hz})(\%)\end{array}$}} & \multirow{2}{*}{\multicolumn{2}{|c|}{$\begin{array}{c}f_{6} \\
(\mathrm{~Hz})(\%)\end{array}$}} \\
\hline & & & & & & & & & & & & \\
\hline & 7919 & - & 15033 & - & 20,284 & - & 25,285 & - & 32,398 & - & 36,710 & - \\
\hline TLE & 8192 & 3.4 & 16,199 & 7.8 & 20,337 & 0.3 & 25,060 & -0.9 & 31,171 & -3.8 & 36,792 & 0.2 \\
\hline TIED & 8301 & 4.8 & 17,397 & 15.7 & 21,451 & 5.8 & 27,006 & 6.8 & 31,239 & -3.6 & 36,998 & 0.8 \\
\hline
\end{tabular}

\section{Conclusions}

The TLE method was proposed to represent the contact stiffness and friction damping of the threaded connection of a projectile-fuse system. Combining the thread elastic model and TLE principle, a method for determining the TLE material parameters was established. The accuracy and reliability of the material parameters were verified based on modal experiments of threaded tubes. The TLE modeling method was applied to evaluate the 
vibration response characteristics of the projectile-fuse system. The simulation results were in good agreement with the experimental results for a projectile penetrating a semi-infinite concrete target. The results can be summarized as follows:

(1) Several modal tests of threaded tubes were performed to investigate the nonlinear response characteristics of threaded connections. The results indicate that the frictional damping and contact stiffness had a significant impact on the dynamic characteristics, causing the resonance frequency and resonance peak to decrease.

(2) An effective method for determining the TLE material parameters was established based on the thread elastic model and TLE principle. Threaded tubes with different specifications were used to verify the accuracy and reliability of the material parameters. The errors were within $5 \%$, indicating the accuracy of the material parameters.

(3) The experimental deceleration signal mainly consisted of the shock response and vibration response. The shock response frequency depended on the frequency of the penetration excitation signal. The vibration response was a damped vibration with the first-order axial vibration frequency as the base frequency.

(4) A reasonable force distribution method for a projectile nose node was proposed. Compared with the equal distribution method, the proposed method could better simulate the penetration excitation force. This study thus provides a reference for the reasonable distribution of the penetration excitation force in dynamic analyses of projectile-fuse systems.

(5) Frequency response analysis of the projectile-fuse system was performed using the TLE. The maximum error in the resonant frequencies between the TLE method and experiment was $7.8 \%$, whereas the maximum error between the existing 'TIED' constraint method and the experiment was $15.7 \%$. In addition, the resonant peak distribution obtained by the TLE method was in better agreement with the frequency distribution of the experimental deceleration signal.

Author Contributions: Conceptualization, A.Y. and A.P.; Methodology, A.Y.; Software, A.P.; Validation, A.P., F.H. and X.W.; Writing—original draft preparation, A.Y.; Writing-review and editing, A.P. and H.Y.; Supervision, F.H. and X.W.; project administration, F.H. and X.W.; funding acquisition, A.P. All authors have read and agreed to the published version of the manuscript.

Funding: This research received no external funding.

Conflicts of Interest: The authors declare no conflict of interest.

\section{References}

1. Ibrahim, R.A.; Pettit, C.L. Uncertainties and dynamic problems of bolted joints and other fasteners. J. Sound Vib. 2005, 279, 857-936. [CrossRef]

2. Zheng, Q.; Guo, Y.C.; Wei, Y.P.; Wang, Y.C.; Wang, X. Loosening of steel threaded connection subjected to axial compressive impact loading. Int. J. Impact Eng. 2020, 14, 103662. [CrossRef]

3. Zhang, D.M.; Gao, S.Q.; Niu, S.H.; Liu, H.P. Study on collision of threaded connection during impact. Int. J. Impact Eng. 2017, 106, 133-145.

4. Guo, Y.C.; Wei, Y.P.; Yang, Z.; Huang, C.G.; Wu, X.Q.; Yin, Q.Y. Nonlinearity of interfaces and force transmission of bolted flange joints under impact loading. Int. J. Impact Eng. 2017, 109, 214-223. [CrossRef]

5. Catania, G.; Strozzi, M. Damping oriented design of thin-walled mechanical components by means of multi-layer coating technology. Coatings 2018, 8, 73. [CrossRef]

6. Yu, L.M.; Ma, Y.; Zhou, C.G.; Xu, H.B. Damping efficiency of the coating structure. Int. J. Solids Struct. 2005, 42, 3045-3058. [CrossRef]

7. Rongong, J.A.; Goruppa, A.A.; Buravalla, V.R.; Tomlinson, G.R.; Jones, F.R. Plasma deposition of constrained layer damping coatings. Proc. Inst. Mech. Eng. Part C J. Mech. Eng. Sci. 2004, 218, 669-680. [CrossRef]

8. Chaaban, A.; Muzzo, U. Finite Element Analysis of Residual Stresses in Threaded End Closures. J. Press. Vessel. Technol. 1991, 113, 398-401. [CrossRef]

9. Brutti, C.; Salvini, P. Dynamic Behaviour Of Tubular Threaded Joints. In Proceedings of the 2nd International Offshore and Polar Engineering Conference, International Society of Offshore and Polar Engineers, San Francisco, CA, USA, 14-19 June 1992; pp. 306-311. 
10. Peng, Y.; Wu, H.; Fang, Q.; Gong, Z.M. Deceleration time of projectile penetration/perforation into a concrete target: Experiment and discussions. Adv. Struct. Eng. 2018, 22, 112-125. [CrossRef]

11. Ahmadian, H.; Jalali, H. Generic element formulation for modelling bolted lap joints. Mech. Syst. Signal Process. 2007, 21, 2318-2334. [CrossRef]

12. Iranzad, M.; Ahmadian, H. Identification of nonlinear bolted lap joint models. Comput. Struct. 2012, 96-97, 1-8. [CrossRef]

13. Bograd, S.; Reuss, P.; Schmidt, A.; Gaul, L.; Mayer, M. Modeling the dynamics of mechanical joints. Mech. Systems Signal Process. 2011, 25, 2801-2826. [CrossRef]

14. Gaul, L.; Schmidt, A. Finite element simulation and experiments on rotor damping assembled by disc shrink fits. Mech. Syst. Signal Process. 2019, 127, 412-422. [CrossRef]

15. Desai, C.S. Thin-layer element for interfaces and joints. Int. J. Numer. Anal. Methods Geomech. 1984, 8, 19-43. [CrossRef]

16. Zhao, G.; Xiong, Z.L.; Jin, X.; Hou, L.T. Prediction of contact stiffness in bolted interface with natural frequency experiment and FE analysis. Tribol. Int. 2018, 127, 157-164. [CrossRef]

17. Alamdari, M.M.; Li, J.C.; Samali, B.; Ahmadian, H.; Naghavi, A. Nonlinear joint model updating in assembled structures. J. Eng. Mech. 2013, 140, 04014042. [CrossRef]

18. Schmidt, A.; Bograd, S.; Gaul, L. Measurement of join patch properties and their integration into finite-element calculations of assembled structures. Shock Vib. 2014, 19, 1125-1133. [CrossRef]

19. Adel, F.; Shokrollahi, S.; Majid, J.O.; Hamid, A. A model updating method for hybrid composite/aluminum bolted joints using modal test data. J. Sound Vib. 2017, 396, 172-185. [CrossRef]

20. Cornel, M.I.; Gillich, G.R.; Maia, N.M.M. A method for an accurate estimation of natural frequencies using swept-sine acoustic excitation. Mech. Syst. Signal Process. 2019, 116, 693-709.

21. Chen, W.; Deng, X. Structural damping caused by micro-slip along frictional interfaces. Int. J. Mech. Sci. 2005, 47, 1191-1211. [CrossRef]

22. Sopwith, D. The distribution of load in screw threads. Proc. Inst. Mech. Eng. 1948, 159, 373-383. [CrossRef]

23. Yamatoto, A. The Theory and Computation of Threads Connection; Yokendo Press: Tokyo, Japan, 1980.

24. Zhang, D.M.; Gao, S.Q.; Xu, X. A new computational method for threaded connection stiffness. Adv. Mech. Eng. 2016, 8, 1-9. [CrossRef]

25. Lu, S.K.; Hua, D.X.; Li, Y.; Cui, F.Y.; Li, P.Y. Stiffness calculation model of thread connection considering friction factors. Math. Probl. Eng. 2019, 2019, 1-19. [CrossRef]

26. Mayer, M.H.; Gau, L.L. Segment-to-segment contact elements for modelling joint interfaces in finite element analysis. Mech. Syst. Signal Process. 2007, 21, 724-734. [CrossRef]

27. Jiang, D.; Wu, S.Q.; Shi, Q.F.; Fei, Q.G. Parameter identification of bolted-joint based on the model with thin-layer elements with isotropic constitutive relationship. J. Vib. Shock 2014, 33, 35-40.

28. Yao, X.; Wang, J.; Zhai, X. Research and application of improved thin-layer element method of aero-engine bolted joints. Proc. Inst. Mech. Eng. Part G J. Aerosp. Eng. 2016, 231, 823-839. [CrossRef]

29. Shokrollahi, S.; Adel, F. Finite element model updating of bolted lap joints implementing identification of joint affected region parameters. J. Theor. Appl. Vib. Acoust. 2016, 2, 65-78.

30. Zou, Q.; Sun, T.S.; Nassar, S.A.; Barber, G.C.; Gumul, A.K. Effect of Lubrication on Friction and Torque-Tension Relationship in Threaded Fasteners. Tribol. Trans. 2007, 50, 127-136. [CrossRef]

31. Liu, B.; Yang, L.M.; Li, D.J. Analysis of axial vibration frequency for projectile structure in penetration. Explos. Shock Waves 2018, $38,677-682$.

32. Forrestal, M.J.; Luk, V.K. Penetration into soil targets. Int. J. Impact Eng. 1992, 12, 427-444. [CrossRef]

33. Forrestal, M.J.; Brar, N.S.; Luk, V.K. Penetration of Strain-Hardening Targets With Rigid Spherical-Nose Rods. J. Appl. Mech. 1991, 58, 7-10. [CrossRef]

34. Forrestal, M.J.; Altman, B.S.; Cargile, J.D.; Hanchak, S.J. An empirical equation for penetration depth of ogive-nose projectiles into concrete targets. Int. J. Impact Eng. 1994, 15, 395-405. [CrossRef]

35. Li, Q.M.; Chen, X.W. Dimensionless formulae for penetration depth of concrete target impacted by a non-deformable projectile. Int. J. Impact Eng. 2003, 28, 93-116. [CrossRef] 